\title{
Effect of the ceramic grain size and concentration \\ on the dynamical mechanical and dielectric behavior of poly(vinilidene fluoride) $\mathrm{Pb}\left(\mathrm{Zr}_{0.53} \mathrm{Ti}_{0.47}\right) \mathrm{O}_{3}$ composites
}

\author{
S. Firmino Mendes • C.M. Costa - V. Sencadas •
}

J. Serrado Nunes · P. Costa • R. Gregorio Jr. •

J.L. Gomez Ribelles • S. Lanceros-Méndez

Published online: 9 July 2009

(C) Springer-Verlag 2009

\section{Erratum to: Appl Phys A}

DOI 10.1007/s00339-009-5141-2

The correct List of Authors, Institutions and Acknowledgements for the paper are presented here.

Acknowledgements The authors thank the Portuguese FCT Grant POCI/CTM/5 9425/2004, PTDC/CTM/69316/2006, FAPESP, CNPq, and the COST-12 action "Structuring Polymers" for financial aid V. Sencadas and S. Firmino Mendes thank to FCT grants SFRH/BD/ $16543 / 2004$ and SFRH/BD/22506/2005, respectively. JLGR acknowledges the support of the Spanish Ministry of Science through project No. MAT2007-66759-C03-01 (including the FEDER financial support).

The online version of the original article can be found under doi:10.1007/s00339-009-5141-2.

S. Firmino Mendes · C.M. Costa · V. Sencadas .

J. Serrado Nunes · P. Costa · S. Lanceros-Méndez ( $₫)$

Department of Physics, Universidade do Minho, Campus de Gualtar, 4710-057 Braga, Portugal

e-mail: lanceros@ fisica.uminho.pt

Fax: +351-253-604061

C.M. Costa

CeNTI-Centre for Nanotechnology and Smart Materials,

Rua Fernando Mesquita 2785, 4760-034 Vila Nova de Famalicão,

Portugal

\section{R. Gregorio Jr.}

Department of Materials Engineering, Universidade Federal

de São Carlos, C.P. 676, 13.565-905 São Carlos, SP, Brasil

J.L. Gomez Ribelles

Centro de Biomateriales, Universidad Politécnica de Valencia,

46022 Valencia, Spain

\section{J.L. Gomez Ribelles}

Regenerative Medicine Unit, Centro de Investigación Príncipe

Felipe, Autopista del Saler 16, 46013 Valencia, Spain

J.L. Gomez Ribelles

CIBER en Bioingenieria, Biomateriales y Nanomedicina,

Valencia, Spain 